\title{
Article
}

\section{Effect of Solvent Additives on the Solution Aggregation of Phenyl-C61-Butyl Acid Methyl Ester (PCBM)}

\author{
Naga Rajesh Tummala, Christopher Sutton, Saadullah G.
}

Aziz, Michael F. Toney, Chad Risko, and Jean-Luc Bredas

Chem. Mater., Just Accepted Manuscript • DOI: 10.1021/acs.chemmater.5b03254 • Publication Date (Web): 24 Nov 2015

Downloaded from http://pubs.acs.org on December 8, 2015

\section{Just Accepted}

"Just Accepted" manuscripts have been peer-reviewed and accepted for publication. They are posted online prior to technical editing, formatting for publication and author proofing. The American Chemical Society provides "Just Accepted" as a free service to the research community to expedite the dissemination of scientific material as soon as possible after acceptance. "Just Accepted" manuscripts appear in full in PDF format accompanied by an HTML abstract. "Just Accepted" manuscripts have been fully peer reviewed, but should not be considered the official version of record. They are accessible to all readers and citable by the Digital Object Identifier (DOI®). "Just Accepted" is an optional service offered to authors. Therefore, the "Just Accepted" Web site may not include all articles that will be published in the journal. After a manuscript is technically edited and formatted, it will be removed from the "Just Accepted" Web site and published as an ASAP article. Note that technical editing may introduce minor changes to the manuscript text and/or graphics which could affect content, and all legal disclaimers and ethical guidelines that apply to the journal pertain. ACS cannot be held responsible for errors or consequences arising from the use of information contained in these "Just Accepted" manuscripts. 


\title{
Effect of Solvent Additives on the Solution Aggregation of Phenyl-C 61 -Butyl Acid Methyl Ester (PCBM)
}

\author{
Naga Rajesh Tummala, ${ }^{1}$ Christopher Sutton, ${ }^{1}$ Saadullah G. Aziz, \\ Michael F. Toney, ${ }^{3}$ Chad Risko, ${ }^{4, *}$ and Jean-Luc Bredas ${ }^{5, *}$
}

\author{
${ }^{1}$ School of Chemistry and Biochemistry \\ Center for Organic Photonics and Electronics \\ Georgia Institute of Technology, \\ Atlanta, Georgia 30332-0400 \\ ${ }^{2}$ Department of Chemistry \\ King Abdulaziz University \\ Jeddah 21589, Kingdom of Saudi Arabia \\ ${ }^{3}$ Stanford Synchrotron Radiation Light Source \\ SLAC National Accelerator Laboratory \\ Menlo Park, California 94025 \\ ${ }^{4}$ Department of Chemistry \& \\ Center for Applied Energy Research (CAER) \\ University of Kentucky \\ Lexington, Kentucky 40506-0055 \\ ${ }^{5}$ Solar and Photovoltaics Engineering Research Center \\ Division of Physical Science and Engineering \\ King Abdullah University of Science and Technology \\ Thuwal 23955-6900, Kingdom of Saudi Arabia
}

*Corresponding authors: chadrisko@uky.edu, jean-luc.bredas@kaust.edu.sa 


\begin{abstract}
High-boiling point solvent additives, employed during the solution processing of active-layer formulations, impact the efficiency of bulk hetero-junction (BHJ) organic solar cells by influencing the morphological / topological features of the multicomponent thin film. Here, we aim at a better understanding of how these additives change the aggregation landscape in the casting solution prior to film deposition via a multi-scale computational study of the aggregation phenomena of phenyl- $\mathrm{C}_{61}$-butyric-acid methyl ester (PCBM) in various solutions. The energetic landscape of PCBM-solvent / solvent-additive intermolecular interactions is evaluated at the electronic-structure level through symmetry-adapted perturbation theory to determine the nature and strength of non-covalent forces important to aggregation. Molecular dynamics simulations highlight how the choice of solvent and solvent additives control the formation of molecular aggregates. Our results indicate that high-boiling point solvent additives change the effective interactions among the PCBM and casting-solvent molecules and alter equilibrium PCBM aggregate size in solution.
\end{abstract}




\section{Introduction.}

The potential for roll-to-roll printing and for deposition onto flexible substrates opens the way for organic photovoltaics (OPV) to impact a range of applications including wearable / fabric embedded devices, window coverings, and large-scale building applications. To date, the bulk heterojunction (BHJ) film architecture, developed primarily from spun-cast multicomponent inks, has shown the most promise to offer the required film morphology for efficient, printed OPV. The printing of OPV active layers requires precise control both of the ink formulations and film morphologies derived from multicomponent blends; however, there remain significant challenges to control the BHJ morphology, known to consist of highly variable material phases, through molecular design and processing protocols. ${ }^{1-7}$

Printed organic solar cells are mainly processed with halogenated solvents, owing to the ability of these solvents to solubilize both the electron-rich donor (usually $\pi$-conjugated small molecules or polymers) and acceptor (typically substituted fullerenes) components; we note that efforts to replace such toxic, hazardous solvents with "green" solvents now show promise. ${ }^{8,9}$ The dilute inclusion of high-boiling point additives, including 1,8-diiodooctane, 1-chloronaphthalene, and dichlorobenzene (also used as solvent), to the casting solvent has been demonstrated to aid in the formation of morphological $1^{10,11}$ and topological ${ }^{12-14}$ film features, leading to improved OPV efficiency. ${ }^{15}$ However, the effects of these additives are blend dependent, with many instances of additives resulting in detrimental morphologies. Given the highly empirical route pursued in the use of these additives, it is not surprising that there is still limited understanding of how the choice of solvent and additives affects aggregation and the formation of the active-layer morphology. ${ }^{9,11-14,16-20}$ 
More generally, issues pertaining to fullerene solubility have been of interest for some time, as aggregation in solution and in the solid state can impact materials properties of fullerenecontaining films. ${ }^{9,20-26}$ Though the solution aggregation of $\mathrm{C}_{60}$ has been studied for more than two decades, ${ }^{20,27}$ there remain many questions concerning the solubility of these highly symmetric, conjugated systems. ${ }^{20,28,29}$ Halogenated aromatic solvents are superior to nonhalogenated solvents for solvating $\mathrm{C}_{60}$, with some exceptions. ${ }^{21,27}$ Various hypotheses, ranging from electron transfer between solvent molecules and fullerenes or anion- $\pi$-interactions, have been put forward to explain the large solubility of fullerenes in halogenated solvents, ${ }^{30,31}$ though correlations between the parameter space explored and solubility are scarce. ${ }^{29}$

Here, to start developing a molecular view of how processing protocols influence the film morphology of fullerene-containing OPV active layers, we report on a multiscale theoretical effort to investigate the solution aggregation of phenyl- $\mathrm{C}_{60}$-butyric acid methyl ester (PCBM), ${ }^{32}$ a widely used, soluble fullerene. $9,23,33-41$ The solvents under consideration are chlorobenzene (CB) and o-dichlorobenzene (DCB), while the additives include 1-chloronaphthalene (1CN) and 1-8-diiodooctane (DIO). We begin by deriving an understanding of the nature and strength of the non-covalent forces at play in fullerene solubility through $a b$ initio symmetry-adapted perturbation theory (SAPT) calculations for model complexes. All-atom molecular dynamics (MD) simulations are then used to evaluate the free energies of PCBM dimer interactions under various solvent conditions, as well as the dynamic formation of fullerene aggregates as a function of concentration and solvent. The combination of these studies provides a molecularscale view of the processes that induce variations in fullerene aggregation in solution, which can influence the morphology and performance of OPV active layers. 


\section{Computational Methodology}

Non-covalent interactions between solvent and solvent-additive molecules with PCBM are analyzed in terms of contributions from exchange-repulsion, London dispersion, electrostatic, and induction effects via symmetry-adapted perturbation theory (SAPT) ${ }^{42}$ with density fitting (which allows for efficient wave-function-based computations). ${ }^{43}$ SAPT calculations were carried out on complexes made of one PCBM molecule and one solvent or additive molecule. The SAPT0 approximation, which does not include the effect of intra-molecular electron correlation, was used given the large system sizes. ${ }^{42,43}$ The SAPT0 calculations were carried out in conjunction with a truncated aug-cc-pVDZ basis set that neglects diffuse functions on hydrogen atoms and diffuse $d$ functions on other atoms, the so-called jun-cc-pVDZ basis set; this basis set was previously shown to give accurate binding energies in non-covalent systems and performed well for the S22 test set of non-covalent interactions when compared to high-quality benchmark data. ${ }^{43-45}$ The jun-cc-pVDZ basis set is not defined for iodine; therefore, SAPT0/juncc-pVDZ calculations were carried out on a chlorine analog of 1,8-diiodooctane - 1,8dichlorooctane $(\mathrm{DClO})$ - to provide an estimate of the interaction potential expected for DIO. The SAPT0 computations were performed with a local version of PSI4. ${ }^{46}$

The relaxed molecular geometries serving as input for the SAPT0 calculations were obtained via density functional theory (DFT), with individual molecules optimized at the B3LYP/6-31G(d,p) level of theory and complexes (e.g., fullerene and solvent or fullerene and additive) optimized at the semi-empirical $\mathrm{PM}^{47}$ level of theory in Gaussian $09 ;^{48}$ the semiempirical calculations were carried out to quickly and robustly span the complex interaction space. Subsequently, the distance between the molecules in the complexes was varied to construct an SAPT0 interaction energy profile as a function of distance between the fullerene and the solvent or additive 
molecule. We note that, due to the system size, SAPT0 calculations were not carried out on fullerene dimers, though fullerene-fullerene interactions are known to be highly attractive $26,27,49$ - a feature that we show, as well, through potential of mean force simulations.

All molecular dynamics (MD) simulations were performed using the GROMACS 4.5.5 software suite. $^{50,51}$ The OPLS-AA (optimized potentials for liquid simulations - all atom) ${ }^{52,53}$ force field was employed for all bond, angle, dihedral, and non-bonded parameters; previous simulations of PCBM with OPLS-AA have validated the use of this force field for such molecules. ${ }^{23,37,39,54}$ The particle mesh Ewald (PME) summation with an accuracy of $10^{-5}$ was applied for long-range electrostatic interactions. A time step of 2 fs was used for most simulations. The switching cutoff was employed for short-range interactions with switching enforced from $1.2 \mathrm{~nm}$ to smoothly truncate the forces and energies to zero at $1.4 \mathrm{~nm}$.

Potential of mean force (PMF) calculations, using constrained simulations in GROMACS ${ }^{51,55}$ within an NPT ensemble (constant number of molecules, pressure, and temperature) at $300 \mathrm{~K}$ and $1 \mathrm{~atm}$, were carried out to determine the free energies of interaction between fullerene molecules as isolated dimers and under varying conditions. The constrained in vacuo simulations consisted solely of two PCBM molecules, while solution simulations included 4800 solvent molecules corresponding to a concentration of $4.2 \times 10^{-4} \mathrm{M}$ (or $4.0 \times 10^{-4} \mathrm{M}$ when 160 solvent additive molecules were considered); these concentrations correspond to less than 0.5 weight percent (wt. \%) PCBM, less than most experiments. The simulations were equilibrated for at least $10 \mathrm{~ns}$ before starting the constrained simulation protocol. Distances between the centers-ofmass of the $\mathrm{C}_{60}$ cages for the two PCBMs were constrained in intervals of $0.05 \mathrm{~nm}$, and the force on each PCBM molecule was recorded at 0.1 ps intervals during the 5 ns simulation. The force 
data from the final 2 ns was averaged and the force profile from these simulations were integrated using the trapezoidal rule to obtain the PMF profile. The PMF between two PCBMs is (arbitrarily) set to zero at a center-to-center distance of $3.0 \mathrm{~nm}$ to set the baseline for the interaction. We note that the loss in entropy (which has a constant value at each distance, defined as $2 k_{B} T \ln \frac{R}{r}$, where $R$ is the distance at which the PMF is set to zero and $r$ is the constrained distance between the two PCBM molecules corresponding to that particular simulation) upon decreasing the constrained distance is not included in the PMF profiles, as it does not affect the nature of the results.

To gain insight into how variations in solvent affect the aggregation of PCBM, simulations were performed for PCBM in pure solvents and solvent-additive mixtures. The simulation cells consisted of 10 PCBM molecules and 800 solvent molecules or 20 PCBM and 1200 solvent molecules, giving PCBM concentrations of $1.23 \times 10^{-2} \mathrm{M}(9.2$ weight $\%$ in $\mathrm{CB})$ and $1.63 \times 10^{-2}$ $\mathrm{M}$ (12 weight $\%$ in $\mathrm{CB}$ and 9.3 weight $\%$ in $\mathrm{DCB})$, respectively; we note that these concentrations represent large PCBM weight fractions, with experimental PCBM weight fractions typically in the range of 1 to 3 weight $\%$ (concentrations such as these would require extremely large simulation boxes with millions of atoms to simulate the aggregation effects of 40 to 80 PCBM molecules). These simulations were performed for 100-200 ns. Larger simulations, also with $1.63 \times 10^{-2} \mathrm{M}$ PCBM concentrations, were performed with 80 or 320 PCBM molecules in 4800 or 19600 (only CB) solvent molecules, respectively, to understand the effect of the number of PCBM molecules on aggregation.

To consider the influence of solvent additives on PCBM aggregation, simulation boxes contained: (i) 10 PCBMs, 20 additive molecules, and $800 \mathrm{CB}$ molecules; (ii) 20 PCBMs, 40 
additive molecules, and $1200 \mathrm{CB}$ molecules; or (iii) 80 PCBMs, 160 additive molecules, and 4800 CB molecules. The PCBM concentrations in the simulations with 1200 (or 4800) solvent molecules correspond to ca. 11.4 weight $\%$ in $\mathrm{CB}: 1 \mathrm{CN}$ and 10.8 weight $\%$ in $\mathrm{CB}: \mathrm{DIO}$, greatly than most experiments. For the largest simulation, which included 320 PCBM molecules, the solvent-additive effect was studied using only DIO (640 solvent additive molecules and 19200 CB molecules). The computational cost of such simulations, with ca. 270,000 atoms, has prevented to date their application to DCB or with the $1 \mathrm{CN}$ additive.

\section{Results \& Discussion}

\subsection{Intermolecular Interactions}

The potential energy surfaces (PES) computed at the SAPT0/jun-cc-pVDZ level of theory (referred to hereafter simply as SAPT0) for fullerene-solvent (either chlorobenzene [CB] or $o$ dichlorobenzene $[\mathrm{DCB}])$ and fullerene-additive interactions are given in Figure 1. To set the baseline, we first focus on interactions between unsubstituted $\mathrm{C}_{60}$ and $\mathrm{CB}$ or DCB. Comparing the depth of the potential wells, the $\mathrm{C}_{60}$-DCB interaction is $0.5 \mathrm{kcal} / \mathrm{mol}$ more stable than $\mathrm{C}_{60}$ with $\mathrm{CB}$. This is a result of the extra chlorine atom in DCB, which increases each of the three stabilizing (electrostatic, dispersion, induction) terms when compared to the CB-fullerene complex, with the largest impact expectedly on the electrostatic and dispersion terms.

Turning to the $\mathrm{C}_{60}$-additive interactions, the strengths of the interactions follow the order 1chloronaphthalene $(1 \mathrm{CN})>$ unsubstituted naphthalene $(\mathrm{NAP})>1,8$-dichlorooctane $(\mathrm{DClO})$. Though DClO lacks $\pi$-character, when compared to DCB (with two chlorine atoms), the results point to similar dispersion strengths, while the centrosymmetric nature of DClO (and the resulting zero dipole moment) leads to limited electrostatic and induction interactions (see the 
electronic supporting information (ESI) for further details). We recall that DClO is being used as a model for DIO (1,8-diiodooctane, see Methodology section) in the SAPT0 calculations. Iodine is known to strengthen intermolecular interactions when compared to chlorine (a function of greater dispersion arising from the more polarizable nature of iodine) - a feature observed in many biomolecular complexes ${ }^{56}-$ at the expense, however, of longer center-to-center distances due to the large van der Waals radius of the iodine atom; ${ }^{56,57}$ the large polarizability of iodine can also lead to stronger halogen bond interactions, due to the large $\sigma$-hole on iodine interacting with the fullerene $\pi$-electrons. ${ }^{58}$ 
Figure 1: Total SAPT0 interaction energy between (middle) $\mathrm{C}_{60}$-solvent and $\mathrm{C}_{60}$-additive complexes and (bottom) PCBM-solvent and PCBM-additive complexes (the total interaction energy is the sum of the electrostatic, dispersion, induction, and exchange energies computed from SAPT0 methodology). Illustrations of the PCBM-solvent and PCBM-additive complexes (white, grey, red, and green spheres represent hydrogen, carbon, oxygen, and chlorine atoms, respectively) are shown in the top panel. 
For both the solvent- and solvent-additive- $\mathrm{C}_{60}$ interactions, the large energetic destabilization at small distances $(<0.6 \mathrm{~nm})$ is due to the exchange-repulsion energy that grows exponentially with orbital overlap. These exchange-repulsion interactions increase for the $\mathrm{C}_{60}$-solvent interactions in identical ways for both $\mathrm{CB}$ and $\mathrm{DCB}$, while the increase is steeper for $1 \mathrm{CN}$ and NAP due to greater number electrons (including the aromatic $\pi$ electrons) that increase the exchange term. Importantly, these destabilizing interactions, which limit $\mathrm{C}_{60}$ solubility, can be offset by favorable additional non-covalent interactions.

This is demonstrated by the PCBM-solvent interactions, where the repulsive wall of the potential energy surface rises at a smaller interaction distance $(\approx 0.64 \mathrm{~nm})$ when compared to the $\mathrm{C}_{60^{-}}$ solvent interactions $(\approx 0.68 \mathrm{~nm})$; we have reported on similar effects - closer packing due to enhanced favorable intermolecular interactions - resulting in tighter solid-state packing of functionalized rubrenes. ${ }^{59}$ These differences are indicative of effects due to the fullerene adduct, and correlate with the higher solubility of PCBM in these solvents, especially for PCBM in $\mathrm{CB}^{26,27,40}$ Interactions between the solvent chlorine atoms and the phenyl moiety on the PCBM adduct also lead to the wide, flat attractive potential from 0.6 to $0.7 \mathrm{~nm}$ for $\mathrm{CB}$ (the effect is similar, though to a lesser extent, for DCB), as opposed to the more pronounced Lennard-Jones style valley observed for $\mathrm{C}_{60}$-solvent interactions. Notably, the repulsive part of the PCBM-CB potential onsets at a longer center-to-center distance compared to PCBM-DCB (ca. $0.02 \mathrm{~nm}$ longer). The attraction at relatively shorter distances for the PCBM-DCB complex indicates that DCB can form a tighter and less dynamic solvent shell around $\mathrm{PCBM},{ }^{28}$ an important characteristic for fullerene solubility; 
Turning to the PCBM-additive interactions, while DClO reveals a tendency for much weaker binding with PCBM when compared to $\mathrm{CB}$ and $\mathrm{DCB}, 1 \mathrm{CN}$ (in particular) and NAP interact rather strongly and at similar center-of-mass distances, results in line with those of $\mathrm{C}_{60}$. Across the solvents and additives considered, the intermolecular interactions with PCBM tend to be stronger with PCBM when compared to $\mathrm{C}_{60}$, a factor directly attributable to the adduct.

It is important to note that the SAPT0-derived noncovalent intermolecular interactions computed here can be related, in part, to the widely used Hildebrand and Hansen solubility parameters. Connecting SAPT0 interaction energies to the solubility parameters can be done in principle by evaluating the orientations of solute-solute, solute-solvent, and solvent-solvent pairs, and including the average number of neighbors from MD simulations or NMR (nuclear magnetic resonance $)^{60}$ spectroscopy. Such an approach has recently been used by Jackson and co-workers, who showed that a combination of MD simulations and SAPT calculations can lead to reasonable evaluations of the solubility parameters of non-electrolyte solvents. ${ }^{61}$ Along similar lines, new force fields based on SAPT interaction energies are under development, providing the potential for larger-scale simulations that directly take into account such quantum mechanically determined results to evaluate solubility. ${ }^{62-64}$ We have shown with MD simulations using the OPLS-AA force field the ability to evaluate Hildebrand and Hansen parameters for PCBM, DCB, and CB with good qualitative agreement with experiment, ${ }^{23,40}$ and improved force fields should lead to more accurate results. Within this context, the comparisons made here are qualitative, and provide an upper bound of the non-covalent intermolecular interactions that are critical to determining the solubility parameters. In general, while the above discussed results are interesting and will point to critical differences in the discussion that follows, a comprehensive understanding of how the additives change the energetic landscape and miscibility in polymer- 
fullerene mixtures represents a more complex issue that will need to be studied at a much larger level requiring a coarse-grained approach. ${ }^{65}$

\subsection{Potential of Mean Force (PMF)}

To build a profile of PCBM aggregation under varying solvent conditions, we carried out potential of mean force (PMF) simulations that can relay information about effective intermolecular interactions by averaging over the orientational degrees of freedom. The PMF simulations were undertaken (i) in vacuo, (ii) in $\mathrm{CB}$ or DCB solutions, and (iii) in $\mathrm{CB}: 1 \mathrm{CN}$ and CB:DIO solution conditions, in order to build a complete picture of how the fullerene environment impacts the tendency for fullerenes to interact. Figure 2 shows the potential of mean force between two PCBM molecules as a function of the center-of-mass distance computed using only the fullerene cages of PCBM (using the full PCBM center-of-mass does not yield unequivocal information as it is influenced by the instantaneous orientation of the butyric-acidmethyl-ester adduct). Note that positive PMF energies correspond to effective repulsive interactions (e.g., a large energy barrier that undermines the ability to aggregate), while negative energies relate to favorable interactions. 


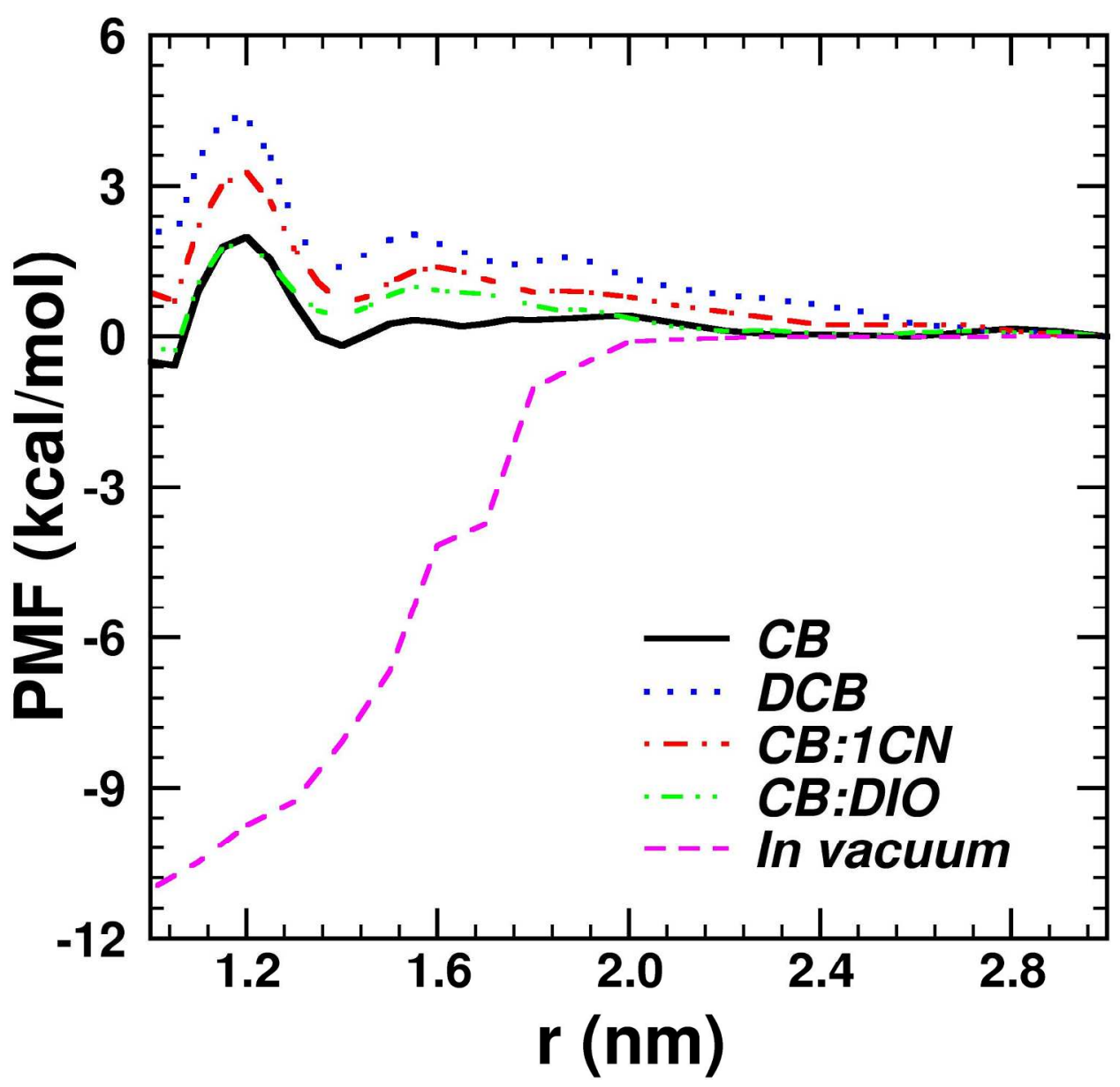

Figure 2: Potential of mean force (PMF) between two PCBM molecules approaching each other computed from constrained simulations and integrating the force acting on the PCBM molecules at each separation. The center-of-mass distance between fullerene cages was considered as the constraint distance.

For the in vacuo simulations, both visual and quantitative analyses indicate that the PCBM molecules effectively sample all the possible orientations at each distance interval. The PMF curve for two PCBM molecules shows a constant, zero PMF beyond $2.0 \mathrm{~nm}$ (distances between centers-of-mass), which is consistent with the fact that PCBM molecules effectively do not interact at such large distances. At distances less than $2.0 \mathrm{~nm}$, the PMF continuously decreases, pointing to an increased attractive potential with decreasing distance. Considering the forces 
acting on only the $\mathrm{C}_{60}$ cages of PCBM (see ESI), the PMF yields a $7.5 \mathrm{kcal} / \mathrm{mol}$ attractive interaction at a $1.0 \mathrm{~nm}$ distance between centers-of-mass (in agreement with existing reports); ${ }^{66}$ taking into account the entire PCBM molecule yields an $11 \mathrm{kcal} / \mathrm{mol}$ attractive interaction. This underlines that the adduct groups increase the favorable attractions in vacuo; indeed, it is adductinduced interactions that lead to the PMF being attractive at $2.0 \mathrm{~nm}$ for PCBM versus $1.5 \mathrm{~nm}$ for bare $\mathrm{C}_{60}$ dimers. ${ }^{66,67}$

The PCBM PMFs show similar trends for all solution conditions considered. The PMF increases gradually as the fullerenes are brought into closer contact from $3.0 \mathrm{~nm}$ to $2.0 \mathrm{~nm}$, followed by a weak oscillatory behavior, see Figure 2. This is in marked contrast with in vacuo PCBM, and indicates the presence of solvent-induced repulsive interactions. Three positive peaks with increasing magnitude are observed at $2.0 \mathrm{~nm}, 1.5$ to $1.6 \mathrm{~nm}$, and $1.2 \mathrm{~nm}$, respectively; note that the larger the peak magnitude, the lower the probability becomes for two PCBM molecules to acquire enough energy/velocity to cross the barrier. The valleys at $1.7 \mathrm{~nm}$ and $1.4 \mathrm{~nm}$ in the PMF correspond to distances where an integer number of solvent layers (evaluated from $\mathrm{C}_{60}$-solvent radial distribution functions) can fit between the two PCBM molecules, similar to what is observed for rigid nanotubes or fullerenes in water. ${ }^{67,68}$ The energy required to remove a layer of the solvent shell and/or additive molecules yields the solvent-induced repulsive interaction and results in the positive peaks in the PMF profile. As the PCBM molecular distance decreases to less than $1.4 \mathrm{~nm}$, it becomes very unfavorable to remove the remaining solvent molecules because of the strong PCBM-solvent interactions. Hence, the PMFs show high, positive peaks at very close distances, whose magnitudes are dependent on the type of solvent and the presence of solvent additive. Below $1.1 \mathrm{~nm}$, when the solvent molecules can no longer fit between two PCBMs, keeping the PCBM molecules apart (beyond their in vacuo preferred separation) is 
energetically unfavorable because of: (i) the attractive potential between PCBM molecules; and (ii) the force exerted on the PCBM molecules from the surrounding solvent. Hence, there is a drive for the fullerenes to aggregate, as indicated by the negative slope, once they are able to eschew the solvent molecules between them. These results are consistent with known trends for fullerenes at close distances, ${ }^{9,67}$ and point to the large propensity of PCBM to aggregate once the center-of-mass distance between the approaching PCBM molecules is less than $1.10 \mathrm{~nm}$.

The strong intermolecular interactions between solvent, additive, and PCBM result in strong, solvent-induced repulsive PMF among PCBM molecules in solution, though there are modest differences among the systems studied. The largest solvent-induced barrier to PCBM aggregation occurs in pure DCB, while the smallest barrier is in pure CB; based on Boltzmann statistics, the $5 \mathrm{kcal} / \mathrm{mol}$ repulsive interaction in DCB decreases the PCBM aggregation probability by approximately a factor of $10^{3}$ when compared to a repulsion on the order of room temperature (0.6 kcal/mol). Interestingly, equilibrium MD simulations for two PCBMs, in all solvent conditions studied, show PCBM contacts of $1.5 \mathrm{~nm}$ or less to be rare events.

While a flat potential-energy surface minimum is seen for the PCBM-CB interaction in the SAPT0 calculations (Figure 1), we do not observe a similar profile at the maximum barrier between PCBM molecules in CB solvent in the absence of additive molecules; this is mainly due to relatively large thermal vibrations that yield more dynamic solvent molecules close to the adduct moiety. However, the stronger interactions observed between PCBM and CB (due to the adduct) can provide a driving force for the adduct moieties to orient towards the surface of PCBM aggregates, and subsequently within thin films; we note that such tendencies for adduct orientation can influence the interaction with polymer domains and the surfaces of electrodes, 
and play a role in the electronic processes critical to OPV internal quantum efficiency, as observed elsewhere. ${ }^{69,70}$

In CB:DIO, the barrier height for the PCBM-PCBM interactions slightly increases in the range from $2.0 \mathrm{~nm}$ to $1.3 \mathrm{~nm}$ when compared to the pure solvent. However, at distances closer than 1.3 nm, the PMF profiles for CB and CB:DIO overlap. This indicates that DIO molecules are excluded from the inter-PCBM volume and the effective repulsion at close distances arises only from $\mathrm{CB}$. In contrast, $\mathrm{CB}: 1 \mathrm{CN}$ induces long-range repulsion starting at $2.7 \mathrm{~nm}$ between the two PCBMs and yields a larger repulsive barrier at $1.2 \mathrm{~nm}$ (when compared to pure $\mathrm{CB}$ ), showing that the larger aromatic molecule provides for more repulsion at close separation when compared to the linear-chain additive.

The PMF profiles of Figure 2 indicate that the PCBM aggregation process consists of a series of jumps to approach PCBM center-of-mass distances of $1.2 \mathrm{~nm}$ (i.e., to reach the top of the final barrier), and then a downhill process to aggregate. The distance at which the largest repulsion occurs between the two PCBMs, $1.2 \mathrm{~nm}$, corresponds to the PCBM-solvent distance of $0.6 \mathrm{~nm}$ where the strongest PCBM-solvent are observed in the SAPT0 calculations, which suggests that a consistent picture is reached between the SAPT0 calculations and MD simulations. However, one has to be careful interpreting the PMF's shown above, as the PMF is a two-body term and the free energy profile between PCBM molecules could be significantly impacted in the presence of either aggregates or other molecules. Nonetheless, the solvent-PCBM or additive-PCBM interactions, as revealed by the SAPT0 calculations and PMF profiles, determine the equilibrium size at which the solvent / additive molecules form a strongly interacting shell around PCBM aggregates and hinder further aggregation. It is also worth remembering that aggregation is a 
kinetic phenomenon and hence the kinetic arrest upon spin-casting or during other processing might allow for smaller fullerene domains.

\subsection{Aggregation in Solution: Cluster Size}

The aggregation of PCBM in solution is dependent on a multitude of factors, among which the PCBM concentration is important. Here, we examine the aggregation of PCBM in the solution conditions described in Section 2 address how the choice of solvent, additive, and PCBM concentration influences aggregation.

Starting with 10 PCBM molecules in a simulation box that contains 800 solvent molecules (1.23 $\times 10^{-2} \mathrm{M}$ ), the aggregation behavior of PCBM is seen to vary considerably when additives are included. Focusing on the radial distribution function (RDF) of the fullerene cages, the RDF peaks are larger when DIO and $1 \mathrm{CN}$ (at $1.2 \times 10^{-2} \mathrm{M}$ concentration) are added to $\mathrm{CB}$. This result underlines that additives, in spite of providing larger repulsive interactions between two PCBMs, can aid in the aggregation of PCBM (Figure 3a). The coordination number (i.e., the number of nearest neighbors) for PCBM defined by the $\mathrm{C}_{60}$ cages within $1.5 \mathrm{~nm}$, is larger in the presence of DIO and $1 \mathrm{CN}$ than $\mathrm{CB}$ alone (Figure $3 \mathrm{~b})$.

Energy oscillations in the PCBM-PCBM interactions occur on the order of 20-30 ns, in Figure 3c, the lower energy peaks, near $-500 \mathrm{kcal} \mathrm{mol}^{-1}$, correspond to an aggregated PCBM state, while the high energy state at $-400 \mathrm{kcal} \mathrm{mol}^{-1}$ corresponds to the dispersed state (with maximum cluster sizes of two). This indicates that the time scale of PCBM aggregation in these simulations is on the order of a few tens of nanoseconds (Figure 3c). PCBM in CB yields a maximum cluster size of eight. Here, cluster sizes are calculated by identifying the network of PCBM molecules that 
are connected to each other. If the distance between the centers-of-mass of two PCBM molecules is less than $1.1 \mathrm{~nm}$, the molecules are considered as connected; the distance cut-off of $1.1 \mathrm{~nm}$ is based on the first peak in the RDF (Figure 3a). The fluctuations in intermolecular distances suggest that the cluster sizes vary, as the PCBM molecules oscillate between dispersed and aggregated states. The probability of non-aggregated PCBM molecules in these simulations is high $(>0.4)$ due to continuous PCBM aggregation and dissolution events. Comparing the cluster sizes when solvent additives are included (Figure 3d) shows that PCBM aggregates of six, seven, or eight molecules have higher probability in the presence of DIO, whereas in $\mathrm{CB}: 1 \mathrm{CN}$ the distribution is similar to that observed in just CB.

These results, in contrast to the observations from the simulations with only two PCBM molecules, indicate enhanced PCBM aggregation behavior when the additive molecules are included, especially DIO. It is useful to note that the PCBM clusters are not kinetically stable as they break and re-form during the simulation trajectory; hence, clusters smaller than six PCBM are also observed. Clusters of this size (6) are the free energy minima in the aggregation landscape (when 10 PCBM molecules are present) and might point to smaller clusters in as-cast BHJ thin films, ${ }^{71}$ although, as mentioned before, the aggregation landscape in the presence of donor molecules might be different from what is observed here. Visualization of the simulation trajectories provides direct evidence of the multiple aggregation and dissolution events of PCBM within the 100-200 ns of simulation time, indicating dynamic equilibrium as expected during aggregation processes. 
a.)
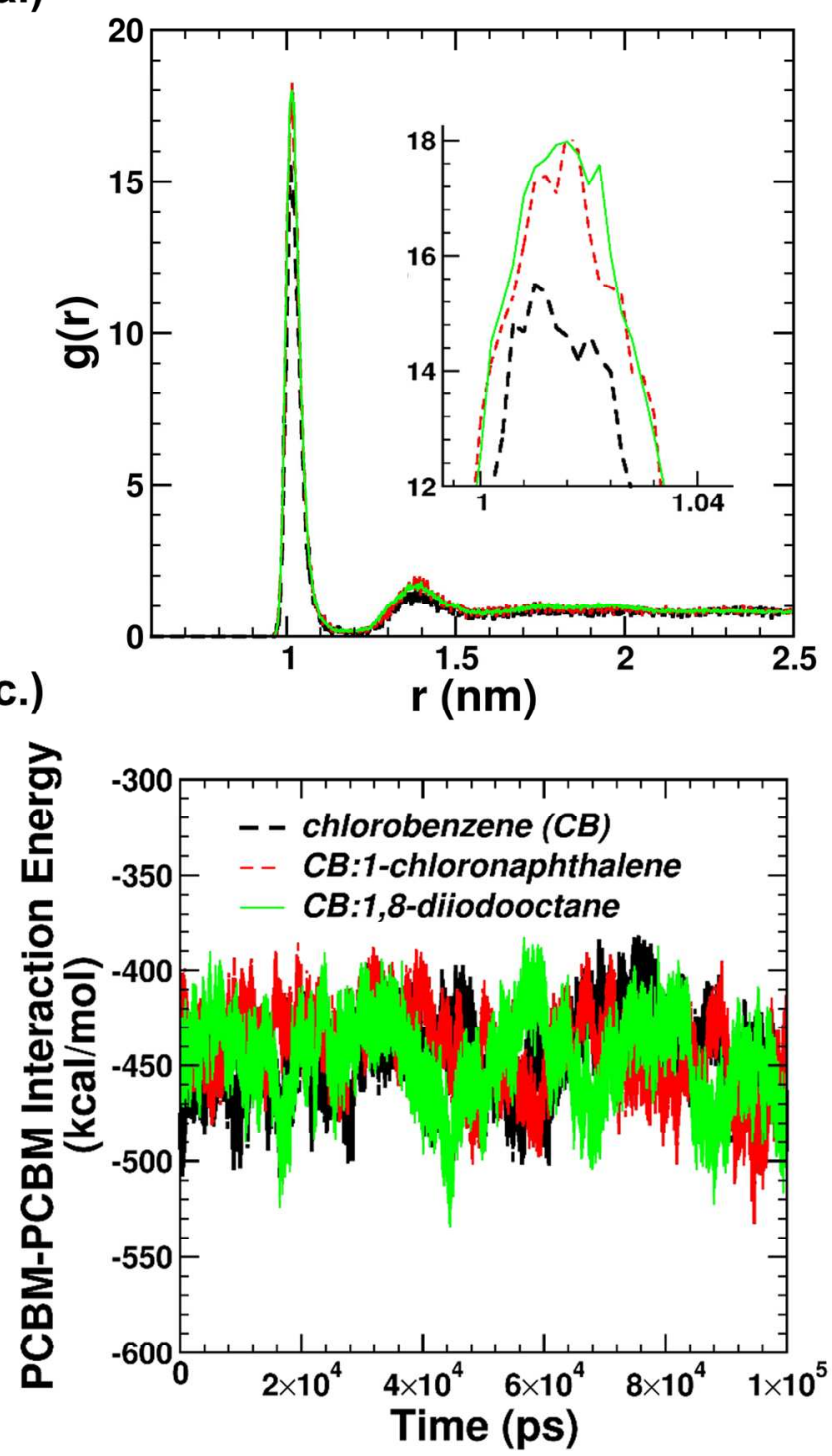

b.)
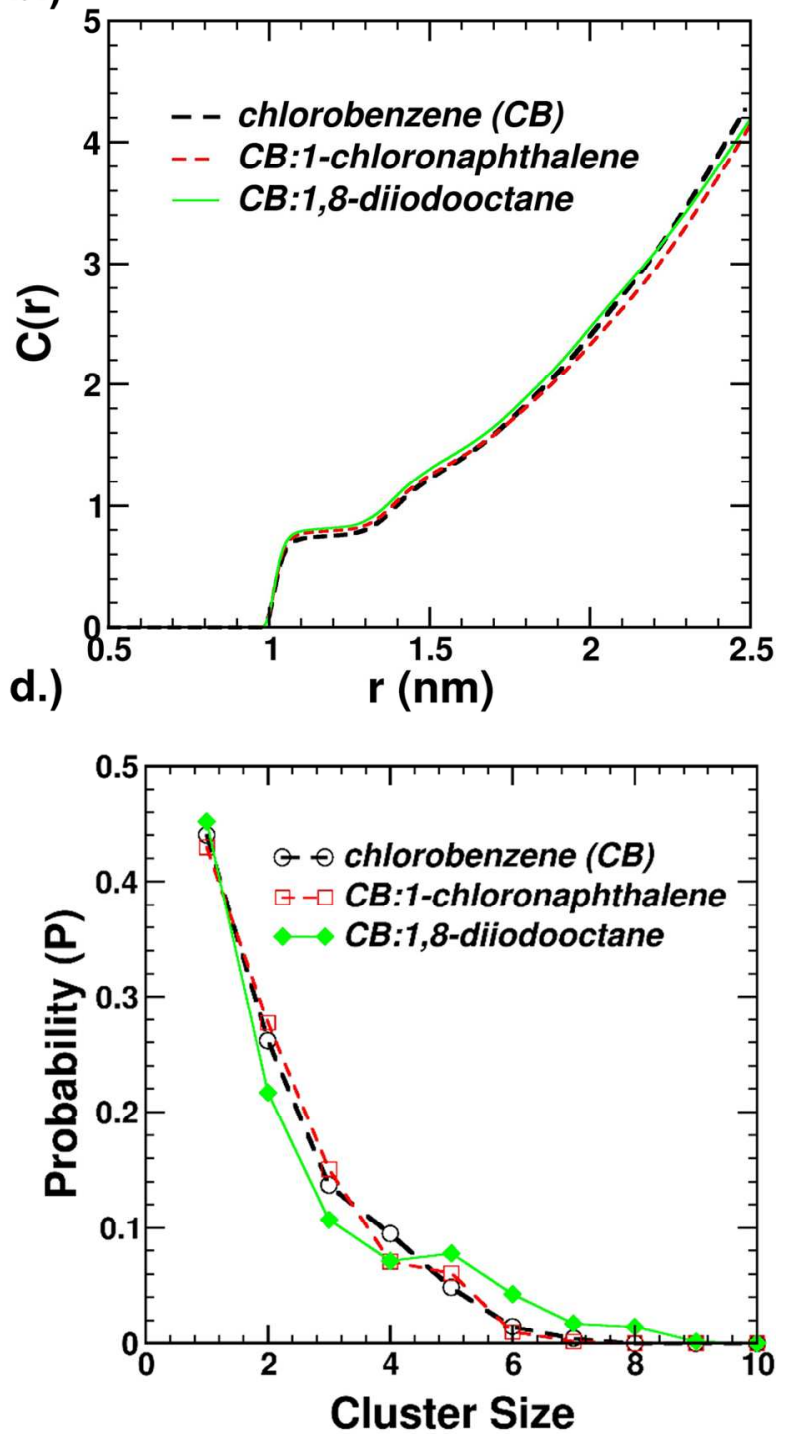

Figure 3: (a) $\mathrm{C}_{60}-\mathrm{C}_{60}$ center-of-mass radial distribution function, $\mathrm{g}(\mathrm{r}$ ) (magnified peak positions in the inset); (b) $\mathrm{C}_{60}-\mathrm{C}_{60}$ center-of-mass nearest neighbor coordination numbers, $\mathrm{C}(\mathrm{r})$; (c) PCBMPCBM interaction energy; and (d) cluster size distribution for 10 PCBM molecules from 3 different simulations containing: (i) no additive, (ii) 40 molecules of 1-chloronaphthalene, and (iii) 40 molecules of DIO, in 800 molecules of CB solvent.

The fullerene mean-square displacements (MSD) as a function of solvent conditions point to differences in the dynamic aggregation character. Fullerene diffusion in the initial 1 to 2 ns is identical for systems with and without additives (Figure S4 in the Supplementary Information, SI). This is in contrast to the fullerene MSD when there are only 2 PCBM molecules in various 
solvent conditions (Figure S3 in the Supplementary Information), in which the MSD follows the order $\mathrm{CB}: \mathrm{DIO}>\mathrm{CB}: 1 \mathrm{CN}>\mathrm{CB}>\mathrm{DCB}$. However, within the $10 \mathrm{PCBM}$ molecule simulations the diffusivity of PCBM in $\mathrm{CB}$ :DIO decreases when compared to the diffusion of PCBM molecules in only CB. Although the absolute magnitude of displacement of PCBM molecules is highest in $\mathrm{CB}: 1 \mathrm{CN}$, the slope of the evolution is similar to that observed for only $\mathrm{CB}$ and hence the diffusivity is not significantly different. This result indicates that additives influence the diffusion of PCBM and aggregation kinetics in rather different ways. The slower diffusion occurs because of larger clusters formed in DIO (see Figure 3d) when compared to PCBM clusters in just CB solvent.

The simulations discussed above involve only 10 PCBMs in solution, and hence aggregation beyond the first shell cannot be quantified. Nonetheless, the results can serve as a useful guide through the complex aggregation processes, as the solubility of fullerenes in these solvents is not well understood. ${ }^{20}$ When the simulations include 20 PCBMs (1200 solvent molecules; 40 additive molecules), the $\mathrm{C}_{60}-\mathrm{C}_{60}$ radial distribution functions (see Figure $4 \mathrm{a}$ ) are larger in $\mathrm{CB}$ compared to DCB, as are the cluster sizes. When additive molecules are present, the magnitude of the first RDF peak is higher in $\mathrm{CB}: 1 \mathrm{CN}$ than in $\mathrm{CB}: \mathrm{DIO}$, though the cluster size analysis (Figure 5a) suggests that the biggest aggregates are found in $\mathrm{CB}: \mathrm{DIO}$ rather than in $\mathrm{CB}: 1 \mathrm{CN}$. The presence of multiple smaller aggregates, apart from the existence of one large cluster, can increase the magnitude of the radial distribution function; to avoid this bias, the cluster-size distributions are important. Hence, the combination of the RDFs and cluster sizes are needed to shed light on the aggregation phenomena. 

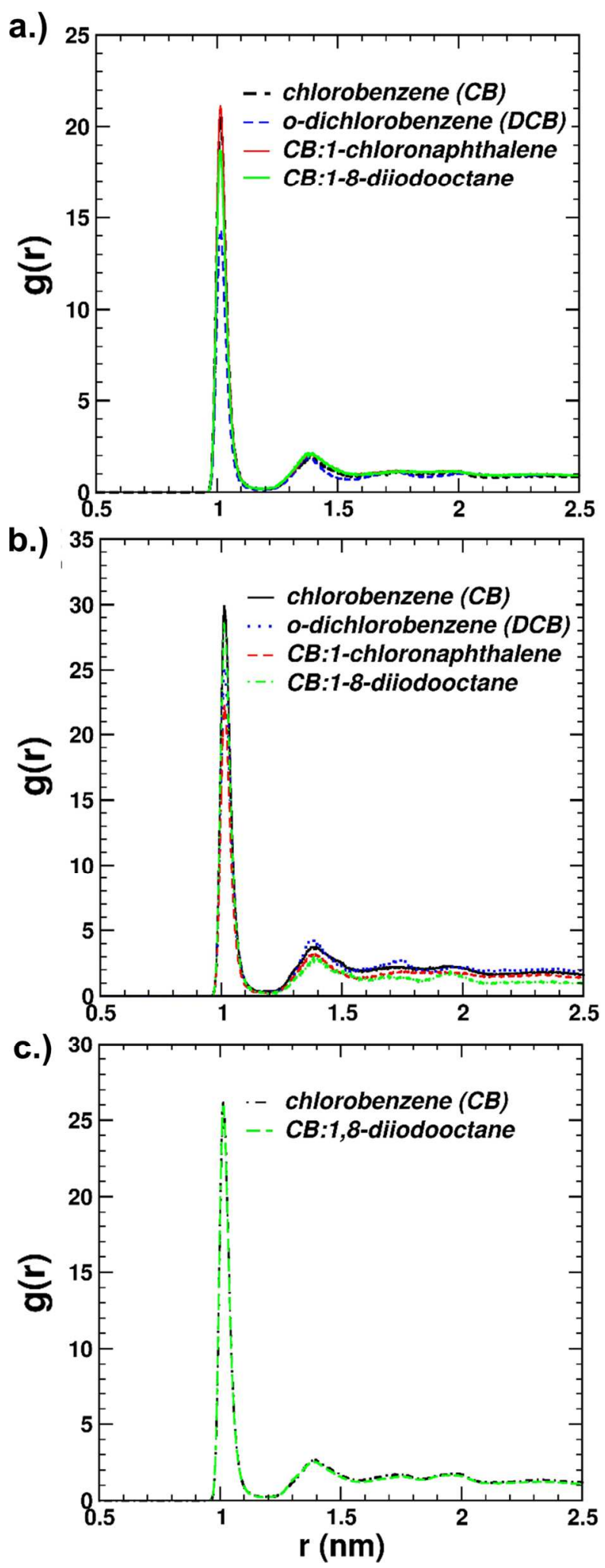

Figure 4: $\mathrm{C}_{60}-\mathrm{C}_{60}$ center-of-mass radial distribution functions, $\mathrm{g}(\mathrm{r}$ ) for: (a) 20; (b) 80; and (c) 320 PCBM molecules in the simulation box with ratios of 1:60 (PCBM:solvent) and 1:2:60 (PCBM:additive:solvent), without and with solvent additive molecules. 
Simulations with 80 PCBM molecules at identical concentrations point to an increase in the RDF magnitude (comparing Figure 4b and Figure 4a), with PCBM in DCB being an exception. The larger RDF peaks at higher PCBM numbers reveals finite-size effects in the simulations, and shows that increasing the number of PCBM molecules, expectedly, increases aggregation due to larger numbers of PCBM interactions. For PCBM in DCB, surprisingly, the magnitude of the RDF does not increase, suggesting no effective increase in PCBM aggregation when compared to the 20-PCBM molecule simulations.

Larger aggregate sizes are observed in simulations with 80 PCBM molecules, up to 52 PCBM molecules in one cluster, with the biggest aggregates found in pure CB. Even though the largest clusters are observed in $\mathrm{CB}$, the distribution of cluster sizes indicates that all sizes smaller than 52 molecules per cluster are observed during the simulation. In contrast, in DCB: (i) small clusters of less than eight molecules or (ii) clusters with 30-50 PCBM molecules, are generally observed. These differences suggest that there exist variations in cluster size for each solvent, based on the solvent-PCBM and PCBM-PCBM interaction strengths. Along with what is observed in the 20-PCBM molecule simulations, the $80-\mathrm{PCBM}$ results are consistent with smaller PCBM cluster sizes in DCB compared to $\mathrm{CB} ;{ }^{72}$ interestingly, DCB is known to decrease domain sizes when used as additive with chloroform as the solvent. ${ }^{73}$ The analysis of the cluster sizes indicates that the simulations reached equilibrium and that the PCBM molecules are able to diffuse and form large PCBM clusters; thus, cluster sizes of $c a$. 10-30 molecules in DCB can be considered energetically not favorable (given their generally low numbers).

The maximum cluster size is near 36 molecules in $\mathrm{CB}: \mathrm{DIO}$; however, for $\mathrm{CB}: 1 \mathrm{CN}$, cluster sizes with 30-50 molecules are prominent. Even in 80-PCBM simulations, aggregates with 10 to 20 
PCBM molecules are more frequently observed in the presence of DIO compared to larger aggregates, providing an additional contrast to PCBM in pure DCB where aggregates of this size are not observed. The absence of larger clusters with DIO, even though the PCBM molecules can diffuse freely and move closer to other PCBM molecules or existing PCBM clusters during the course of the simulation trajectory, suggests that DIO both aids in the aggregation of small aggregates and effectively shields PCBM molecules from forming large aggregates. In fact, smaller $\mathrm{PC}_{71} \mathrm{BM}$ aggregates are observed in the presence of $\mathrm{DIO}$ when compared to just chlorobenzene. $^{74}$

For large aggregates, the entropy lost upon aggregation is much smaller than the enthalpy gained due to aggregation; therefore, there are no observable dissolution or dispersion events in the 80PCBM simulations, in contrast to what is seen in 10- or 20-PCBM simulations. The formation of such clusters, although partly dynamic, provides support to reports that point to the formation of fullerene aggregates in good solvents. ${ }^{21}$ Notably, the cluster sizes reported here are similar to the aggregate sizes (6 $\mathrm{nm}$ and $5 \mathrm{~nm}$ for PCBM in $\mathrm{CB}$ and DCB solvents, respectively) recently observed in BHJ devices from the analysis of grazing-incidence wide-angle x-ray spectroscopy (GIWAXS) data in CB and DCB solvents. ${ }^{75}$

Finally, the 320-PCBM simulations (Figure 4c) show a decrease in RDF magnitude when compared to the 80 -PCBM simulations. This indicates, along with the cluster-size analysis in Figure 5, that the ratio of aggregates compared to isolated molecules does not increase in 320PCBM simulations. As observed in the 80-PCBM simulations, larger clusters have smaller probabilities in $\mathrm{CB}: \mathrm{DIO}$ than in pure $\mathrm{CB}$, with the largest clusters containing $c a$. 80 molecules in CB:DIO compared to $c a$. 100 PCBM molecules in CB (but with probabilities lower than $10^{-3}$ ). 
Nevertheless, the aggregate sizes are on average only modestly larger than in 80 -PCBM simulations.
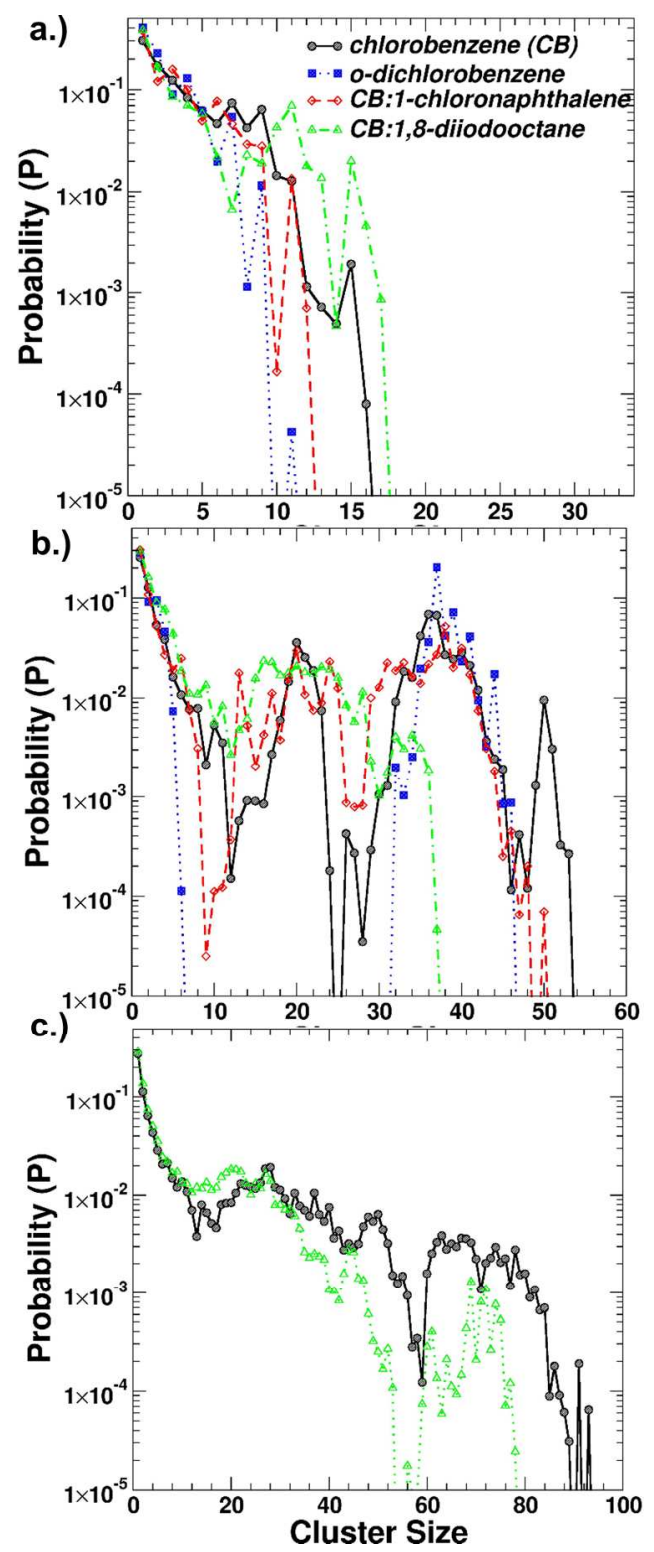

Figure 5: Probability (P) distribution as a function of cluster size in simulations with: (a) 20; (b) 80; and (c) 320 PCBM molecules in the simulation box with ratios of 1:60 (PCBM:solvent) and 1:2:60 (PCBM:additive:solvent), without and with additive molecules. 


\subsection{Aggregation in Solution: Molecular Orientation and Diffusion}

The relative orientation among PCBM nearest neighbors is an important factor that determines many materials properties, including the effective intermolecular electronic couplings critical to charge-carrier transport. ${ }^{23,37,76}$ Hence, it is of interest to quantify potential differences in PCBM orientation in solution-phase aggregates as these could manifest in the solid state. To evaluate the 2D orientational probability distribution for PCBM molecules within PCBM center-of-mass distances of $0.975 \mathrm{~nm}$ and $1.075 \mathrm{~nm}$, a vector going from the center-of-mass coordinates of the fullerene cage to the methano-bridged carbon is used; the orientational distribution for PCBM in $\mathrm{CB}$ is shown as a function of system size in Figure 6. With increasing number of PCBMs, the probability distributions at all distances and angles are identical, except for a minor increase in the orientation density from $40^{\circ}$ to $120^{\circ}$ at a distance of $1.025 \mathrm{~nm}$. On the other hand, the 2D probability plot for PCBM in DCB (Figure 6f) has a dumbbell shape indicating a narrow range of favorable orientations (while the more linear shape in $\mathrm{CB}$ is indicative of a broader range of orientations). Importantly, these shapes change in the presence of DIO, with a maximum orientation probability (circular) around $90^{\circ}$; the orientation change is minimal in the presence of the $1-\mathrm{CN}$ additive.

These differences in orientation probability as a function of solvent environment can propagate to different crystalline structures. Although the exact crystalline structures obtained from experiments cannot be quantified from these MD simulations, the nature of the solid-state packing structure can induce modifications of the electronic environment in terms of the ionization (and polarization) energies, electronic couplings, site energies, and other intrinsic and extrinsic electronic parameters. These differences, in turn, can result in variations in exciton dissociation properties (as the size of PCBM domains and the orientation of the adduct chains 
impact the charge separation ability) $)^{77}$ and in charge-carrier transport properties of active layers developed under different processing conditions. We note that such seemingly subtle changes in processing have been shown to lead to variations in electron mobilities determined in thin-film PCBM transistors. ${ }^{23,41,78}$

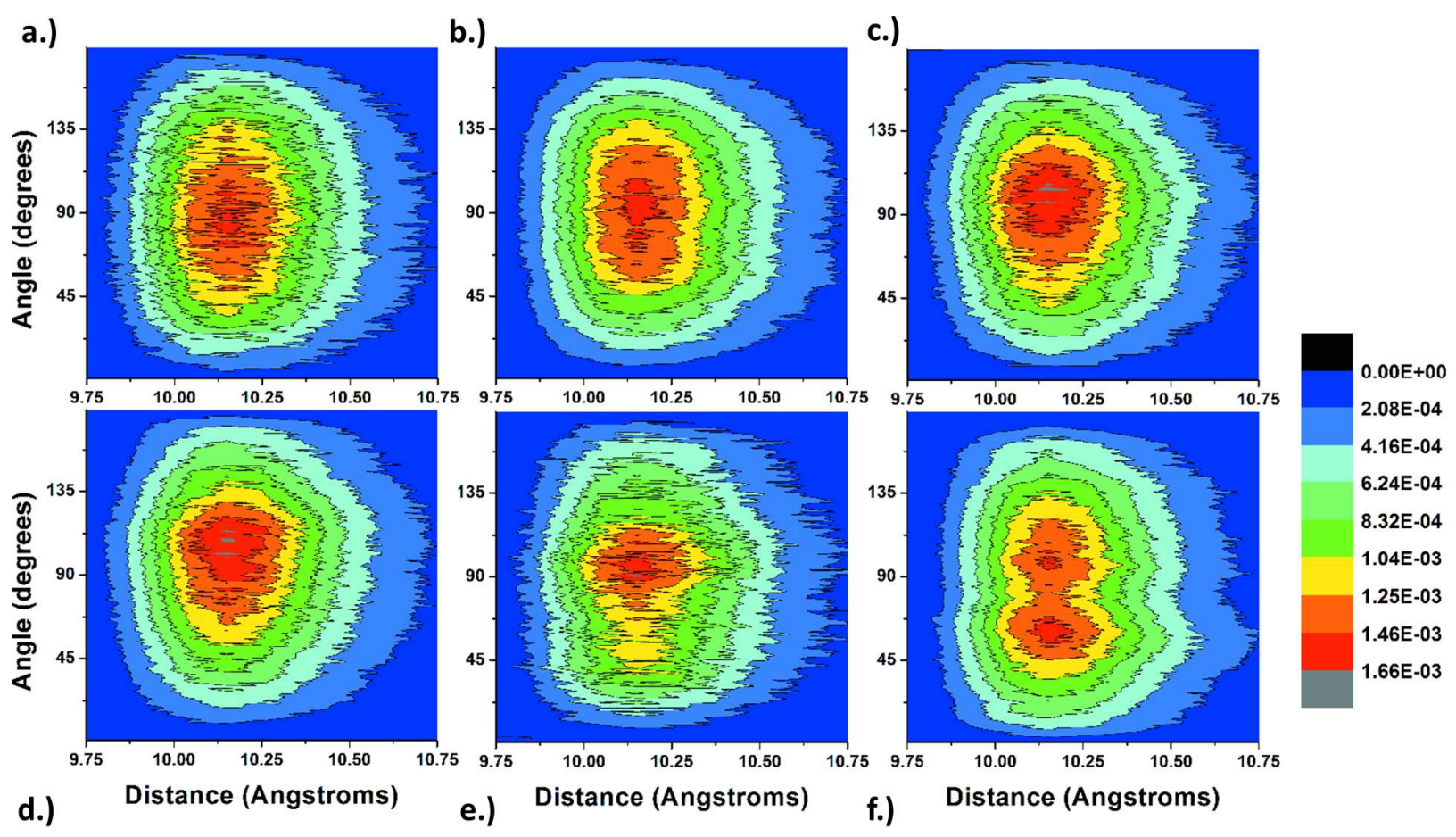

Figure 6: Two-dimensional (2D) orientational distribution function for: (a) 20 PCBM molecules in $1200 \mathrm{CB}$ solvent molecules; (b) 80 PCBM molecules in $4800 \mathrm{CB}$ solvent molecules; (c) 320 PCBM molecules in $19200 \mathrm{CB}$ solvent molecules; (d) 80 PCBM molecules in $4800 \mathrm{CB}$ molecules and 160 1CN molecules; (e) 80 PCBM molecules in $4800 \mathrm{CB}$ molecules and 160 1,8DIO molecules; and (f) 80 PCBM molecules in 4800 DCB molecules.

Apart from establishing differences in aggregate size and molecular orientation of PCBM in various solvent formulations, another important quantification of the solvent effects is to 
understand the shape of the aggregates within different solvent conditions. We present in the SI plots of the number of molecules observed as a function of the distance from the center-of-mass of the largest aggregate, as well as representative simulation snapshots from the 80 -PCBM simulations. The results indicate that PCBM aggregates are more three-dimensional (3D) in DCB and more two-dimensional (2D) in $\mathrm{CB}$, and that the presence of additives in $\mathrm{CB}$ does not really affect the shape of the aggregate (Figure S2 and Figure S3). Interestingly, PCBM is known to crystallize in monoclinic and triclinic co-crystal structures ${ }^{79}$ when grown from DCB and CB, respectively. The monoclinic 1:1 PCBM:DCB co-crystal is more anisotropically packed and has more $2 \mathrm{D}$ features in comparison to the $3 \mathrm{D}$ packed triclinic co-crystal (2:1, PCBM:CB); we do note, however, that solvent-free PCBM crystallites grown from DCB are more similar with the triclinic co-crystal structure grown from $\mathrm{CB} .{ }^{80}$ In general, a 3D, isotropic packing is preferable to a 2D packing to insure efficient electron transport through bulk media. ${ }^{23}$

When considering thin-film deposition, the evaporation rate and annealing time are crucial factors, as these directly influence the equilibrium morphology of the active layer. ${ }^{81}$ The molecular property that is most directly related to the time scale of morphology formation is diffusion. Although it is expected that PCBM diffusion in the donor-acceptor mixtures used to create BHJ layers is more complex as compared to PCBM diffusion in solution alone, it is useful to differentiate the diffusion behavior of PCBM in the various solvent conditions considered here, see Figure 7.

The slopes of the straight lines in the plots of mean square displacements (MSD) vs. time in Figure 7 are related to the diffusion constant through Einstein's equation. ${ }^{55}$ The MSDs of the PCBM molecules in $\mathrm{CB}$, regardless of the presence of additives, show no significant difference. 
In fact, the MSD curves are similar when going from simulations containing 20 PCBMs to 320 PCBMs (with respect to the slope in the first 8 to $10 \mathrm{~ns}$ ). The MSD of PCBM molecules in DCB is one-quarter that of PCBM molecules in any of the CB-based simulations. This is due to the increased density and molecular weight of DCB. The slower diffusion of PCBM in DCB indicates the possibility of longer annealing times within the BHJ active layer in the presence of DCB compared to $\mathrm{CB}$. This is line with recent experiments in which the time required to observe the peak crystallinity in $\mathrm{BHJ}$ active later is three times longer in the presence of DCB than $\mathrm{CB} .^{82}$ We note that the solvents considered here have different drying times. ${ }^{83}$ While this work considers the miscibility and aggregation of PCBM under varying solvent conditions, the work cannot account for the kinetic variations of film formation due to these variations. Nevertheless, connecting molecular-scale parameters, interaction strengths, and diffusion to active layer morphology is a very challenging proposition on the basis of all-atom molecular dynamics simulations; as such, studies are ongoing at the coarse-grained level to begin to make these connections. $^{84,85}$ 
a.)

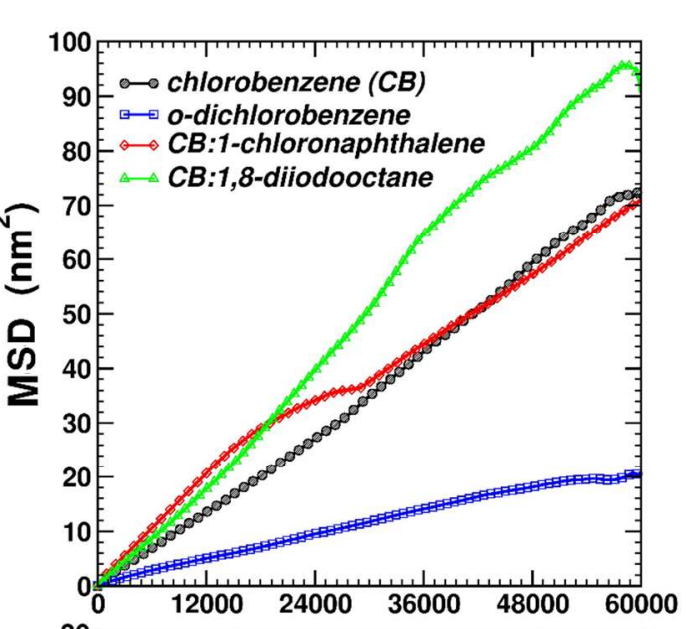

b.)

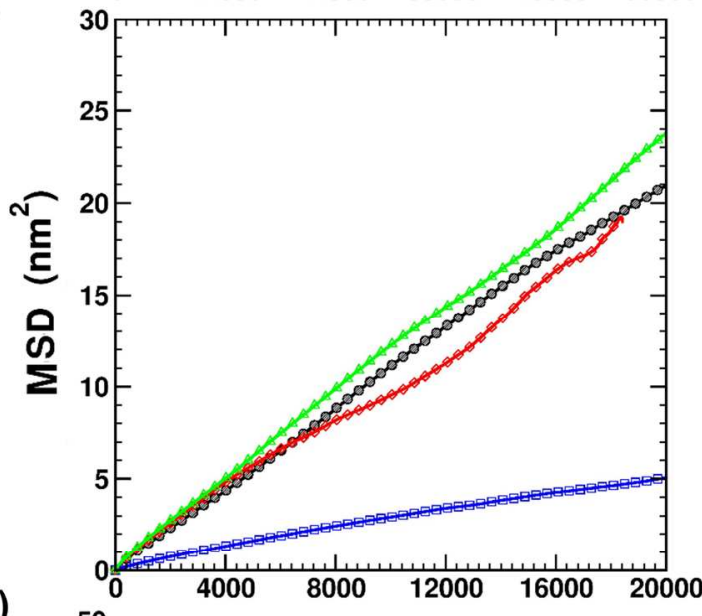

c.)

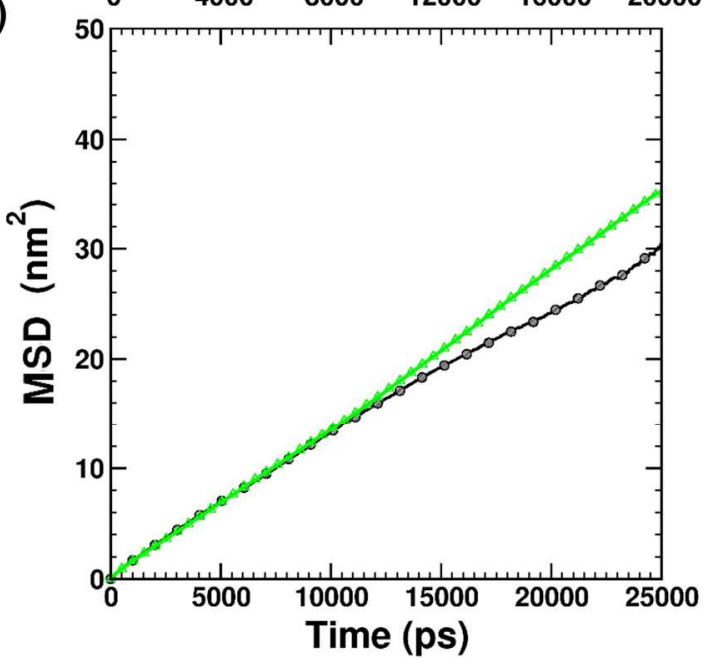

Figure 7: Mean square displacements (MSD) of PCBM molecules in simulations with: (a) 20; (b) 80; and (c) 320 PCBM molecules in the simulation box with ratios of 1:60 (PCBM:solvent) and 1:2:60 (PCBM:additive:solvent), without and with additive molecules. 


\section{Synopsis}

We have carried out a combined electronic-structure and molecular dynamics study to investigate PCBM aggregation under a variety of solvent conditions, including the presence of high-boiling point solvent additives. Our results show that seemingly modest variations in solvent and additive chemical structure can impart notable differences on the propensity for fullerenes to aggregate.

The MD simulations point, in general, to the formation of larger aggregates in cholorobenzene vs. dichlorobenzene, which agrees well with experimental results concerning the domain sizes of PCBM in BHJ active layers processed with $\mathrm{CB}$ or DCB. This is the direct result of the packing proximity between the solvent and PCBM molecules, as highlighted by the differences in the potential energy surfaces and intermolecular interactions (shown at the SAPT0/jun-cc-pVDZ level of theory and in the top-panel of Figure 8). Additive molecules, here 1-chloronaphthalene and 1,8-diiodooctane, effectively decrease the sizes of PCBM aggregates when used in conjunction with $\mathrm{CB}$ (representatively showed in the bottom panel of Figure 8). Similarly, the differences in interaction of solvent and additive molecules with the fullerene, and in particular the adduct moiety, can determine the intermolecular orientations among fullerene molecules. 

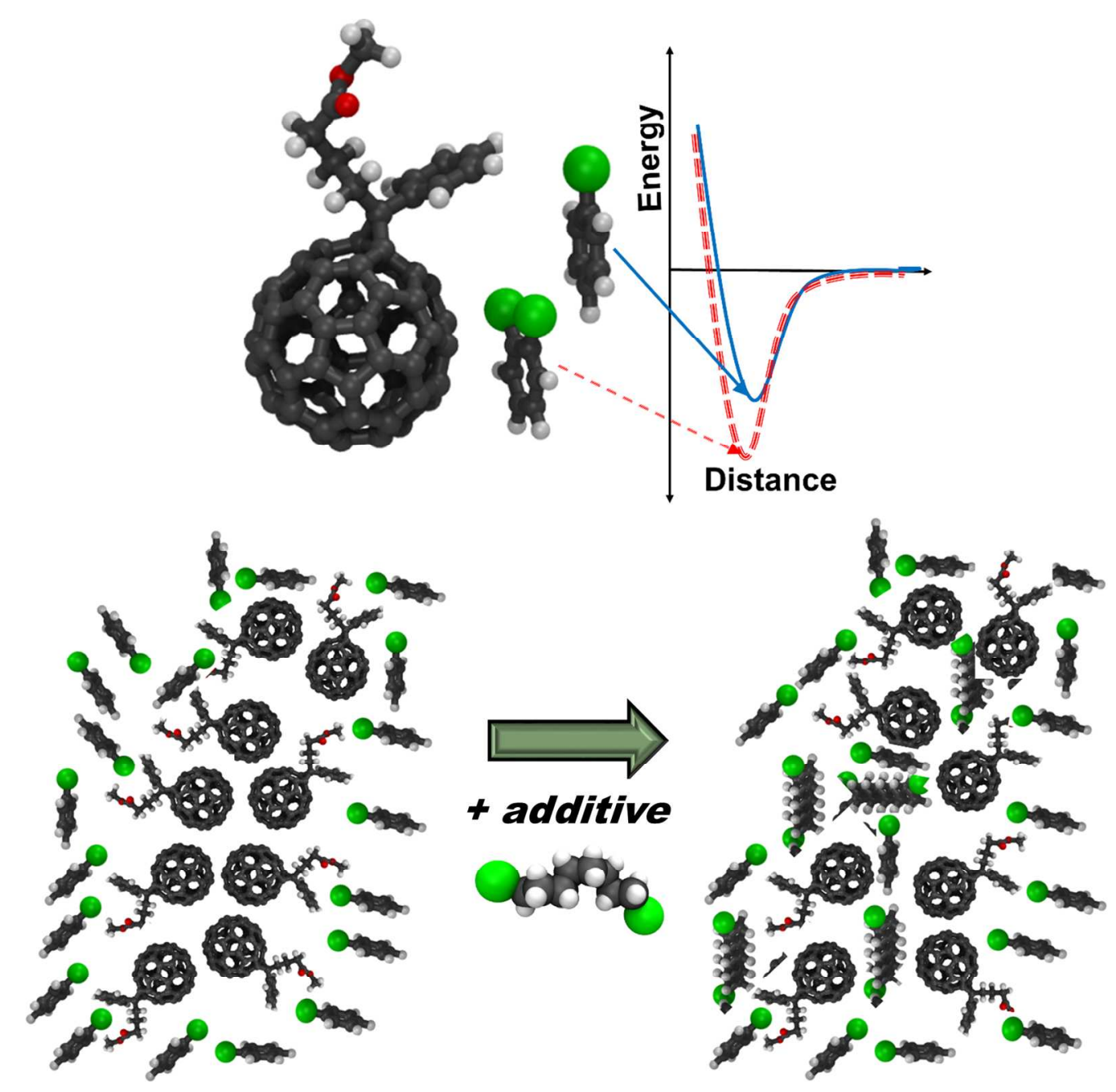

Figure 8: Pictorial representation of key points from this investigation. (top) $o$-Dichlorobenzene has stronger interactions with fullerene cage and can pack at closer distance than chlorobenzene. (bottom) In chlorobenzene, the addition of DIO decreases aggregate sizes and changes the orientation landscape between the individual PCBM molecules.

Overall, our results pave the way toward a better understanding of the roles that various processing solvents and additives play in the formation of solution-processed thin films, which can lead to the design of better solvent systems for the solution processing of organic materials of interest for a host of electronic and optoelectronic applications. While the analysis presented here provides an important step forward, considerable work still needs to be done in order to 
reach control of how changes in chemical and molecular structure impact aggregation in these formulations.

\section{Supplementary Information}

Electrostatic, dispersive, exchange, and induction interaction energies of PCBM-solvent and PCBM-additive molecules evaluated from SAPT0, potential of mean force (PMF) between PCBM molecules in vacuo considering the whole PCBM molecules and only $\mathrm{C}_{60}$ cages, mean square displacement of two PCM molecules under various solvent conditions, averaged mean square displacement of 10 PCBM molecules in 800 solvent molecules and 20 solvent additive molecules when present, number of molecules as a function of distance from the cluster centerof-mass to give an estimate on the fractal dimension of the cluster, and representative simulation snapshots of the PCBM molecular aggregates in various solvent conditions are reported in the Supporting Information. The Supporting Information is available free of charge on the ACS Publications website at DOI: 10.1021/acs.chemmater.xxxxxx

\section{Acknowledgements}

We gratefully acknowledge the support of various parts of this work by the Deanship of Scientific Research of King Abdulaziz University under an International Collaboration Grant (Award No. D-001-433) and the Department of the Navy, Office of Naval Research, under the MURI "Center for Advanced Organic Photovoltaics" (Award No. N00014-14-1-0580). Computing resources were provided through the National Science Foundation Chemistry Research Instrumentation and Facilities (CRIF) Program (Award No. CHE-0946869). C.R. thanks the University of Kentucky Vice President for Research for start-up funds. The work at King Abdullah University of Science and Technology has been supported by KAUST 
competitive research funding and the Office of Naval Research Global (Award No. N62909-15-

1-2003).

\section{References}

1. Søndergaard, R.; Hösel, M.; Angmo, D.; Larsen-Olsen, T. T.; Krebs, F. C., Roll-to-Roll Fabrication of Polymer Solar Cells. Mater. Today 2012, 15, 36-49.

2. Kippelen, B.; Bredas, J.-L., Organic Photovoltaics. Energy Environ. Sci. 2009, 2, 251261.

3. Hoppe, H.; Sariciftci, N. S., Organic Solar Cells: An Overview. J. Mater. Res. 2004, 19 1924-1945.

4. Rivnay, J.; Mannsfeld, S. C. B.; Miller, C. E.; Salleo, A.; Toney, M. F., Quantitative Determination of Organic Semiconductor Microstructure from the Molecular to Device Scale. Chem. Rev. 2012, 112, 5488-5519.

5. Collins, B. A.; Tumbleston, J. R.; Ade, H., Miscibility, Crystallinity, and Phase Development in P3HT/PCBM Solar Cells: Toward an Enlightened Understanding of Device Morphology and Stability. J. Phys. Chem. Lett. 2011, 2, 3135-3145.

6. Schmidt, K.; Tassone, C. J.; Niskala, J. R.; Yiu, A. T.; Lee, O. P.; Weiss, T. M.; Wang, C.; Fréchet, J. M. J.; Beaujuge, P. M.; Toney, M. F., A Mechanistic Understanding of Processing Additive-Induced Efficiency Enhancement in Bulk Heterojunction Organic Solar Cells. Adv.

Mater. 2014, 26, 300-305.

7. Abdelsamie, M.; Treat, N. D.; Zhao, K.; McDowell, C.; Burgers, M. A.; Li, R.; Smilgies, D. M.; Stingelin, N.; Bazan, G. C.; Amassian, A., Toward Additive-Free Small-Molecule Organic Solar Cells: Roles of the Donor Crystallization Pathway and Dynamics. Adv. Mater. 2015, 10.1002/adma.201503395.

8. Chueh, C.-C.; Yao, K.; Yip, H.-L.; Chang, C.-Y.; Xu, Y.-X.; Chen, K.-S.; Li, C.-Z.; Liu, P.; Huang, F.; Chen, Y., et al., Non-Halogenated Solvents for Environmentally Friendly Processing of High-Performance Bulk-Heterojunction Polymer Solar Cells. Energy Environ. Sci. 2013, 6, 3241-3248.

9. Mortuza, S. M.; Banerjee, S., Molecular Modeling Study of Agglomeration of [6,6]Phenyl-C61-Butyric Acid Methyl Ester in Solvents. J. Chem. Phys. 2012, 137, 244308-244312.

10. Perez, L. A.; Chou, K. W.; Love, J. A.; van der Poll, T. S.; Smilgies, D.-M.; Nguyen, T.Q.; Kramer, E. J.; Amassian, A.; Bazan, G. C., Solvent Additive Effects on Small Molecule Crystallization in Bulk Heterojunction Solar Cells Probed During Spin Casting. Adv. Mater. 2013, 25, 6380-6384.

11. Perez, L. A.; Rogers, J. T.; Brady, M. A.; Sun, Y.; Welch, G. C.; Schmidt, K.; Toney, M. F.; Jinnai, H.; Heeger, A. J.; Chabinyc, M. L., et al., The Role of Solvent Additive Processing in High Performance Small Molecule Solar Cells. Chem. Mater. 2014, 26, 6531-6541.

12. Etzold, F.; Howard, I. A.; Forler, N.; Cho, D. M.; Meister, M.; Mangold, H.; Shu, J.; Hansen, M. R.; Müllen, K.; Laquai, F., The Effect of Solvent Additives on Morphology and Excited-State Dynamics in PCPDTBT:PCBM Photovoltaic Blends. J. Am. Chem. Soc. 2012, $134,10569-10583$. 
13. Ye, L.; Zhang, S.; Ma, W.; Fan, B.; Guo, X.; Huang, Y.; Ade, H.; Hou, J., From Binary to Ternary Solvent: Morphology Fine-Tuning of D/A Blends in PDPP3T-Based Polymer Solar Cells. Adv. Mater. 2012, 24, 6335-6341.

14. Liu, X.; Huettner, S.; Rong, Z.; Sommer, M.; Friend, R. H., Solvent Additive Control of Morphology and Crystallization in Semiconducting Polymer Blends. Adv. Mater. 2012, 24, 669674.

15. Lee, J. K.; Ma, W. L.; Brabec, C. J.; Yuen, J.; Moon, J. S.; Kim, J. Y.; Lee, K.; Bazan, G. C.; Heeger, A. J., Processing Additives for Improved Efficiency from Bulk Heterojunction Solar Cells. J. Am. Chem. Soc. 2008, 130, 3619-3623.

16. Chang, L.; Jacobs, I. E.; Augustine, M. P.; Moulé, A. J., Correlating Dilute Solvent Interactions to Morphology and Opv Device Performance. Org. Electron. 2013, 14, 2431-2443.

17. Aïch, B. R.; Lu, J.; Beaupré, S.; Leclerc, M.; Tao, Y., Control of the Active Layer Nanomorphology by Using Co-Additives Towards High-Performance Bulk Heterojunction Solar Cells. Org. Electron. 2012, 13, 1736-1741.

18. Hoven, C. V.; Dang, X.-D.; Coffin, R. C.; Peet, J.; Nguyen, T.-Q.; Bazan, G. C., Improved Performance of Polymer Bulk Heterojunction Solar Cells through the Reduction of Phase Separation Via Solvent Additives. Adv. Mater. 2010, 22, E63-E66.

19. Etxebarria, I.; Ajuria, J.; Pacios, R., Solution-Processable Polymeric Solar Cells: A Review on Materials, Strategies and Cell Architectures to Overcome 10\%. Org. Electron. 2015, $19,34-60$.

20. McHedlov-Petrossyan, N. O., Fullerenes in Liquid Media: An Unsettling Intrusion into the Solution Chemistry. Chem. Rev. 2013, 113, 5149-5193.

21. Guldi, D. M.; Prato, M., Excited-State Properties of C60 Fullerene Derivatives. Acc. Chem. Res. 2000, 33, 695-703.

22. Machui, F.; Maisch, P.; Burgues-Ceballos, I.; Langner, S.; Krantz, J.; Ameri, T.; Brabec, C. J., Classification of Additives for Organic Photovoltaic Devices. ChemPhysChem 2015, 16, 1275-1280.

23. Tummala, N. R.; Mehraeen, S.; Fu, Y. T.; Risko, C.; Bredas, J. L., Materials-Scale Implications of Solvent and Temperature on [6,6]-Phenyl-C61-Butyric Acid Methyl Ester (PCBM): A Theoretical Perspective. Adv. Funct. Mater. 2013, 23, 5800-5813.

24. Roehling, J. D.; Batenburg, K. J.; Swain, F. B.; Moulé, A. J.; Arslan, I., ThreeDimensional Concentration Mapping of Organic Blends. Adv. Funct. Mater. 2013, 23, $2115-$ 2122.

25. Duong, D. T.; Walker, B.; Lin, J.; Kim, C.; Love, J.; Purushothaman, B.; Anthony, J. E.; Nguyen, T.-Q., Molecular Solubility and Hansen Solubility Parameters for the Analysis of Phase Separation in Bulk Heterojunctions. J. Polym. Sci., Part B: Polym. Phys. 2012, 50, 1405-1413.

26. Machui, F.; Langner, S.; Zhu, X.; Abbott, S.; Brabec, C. J., Determination of the P3HT:PCBM Solubility Parameters Via a Binary Solvent Gradient Method: Impact of Solubility on the Photovoltaic Performance. Sol. Energy Mater. Sol. Cells 2012, 100, 138-146.

27. Ruoff, R. S.; Tse, D. S.; Malhotra, R.; Lorents, D. C., Solubility of Fullerene (C60) in a Variety of Solvents. J. Phys. Chem. 1993, 97, 3379-3383.

28. Wang, C. I.; Hua, C. C.; Chen, S. A., Dynamic Solvation Shell and Solubility of C60 in Organic Solvents. J. Phys. Chem. B 2014, 118, 9964-9973.

29. Chaban, V.; Maciel, C.; Fileti, E., Does the Like Dissolves Like Rule Hold for Fullerene and Ionic Liquids? J. Solution Chem. 2014, 43, 1019-1031. 
30. Schottel, B. L.; Chifotides, H. T.; Dunbar, K. R., Anion-П Interactions. Chem. Soc. Rev. 2008, 37, 68-83.

31. Demeshko, S.; Dechert, S.; Meyer, F., Anion-П Interactions in a Carousel Copper(II)-Triazine Complex. J. Am. Chem. Soc. 2004, 126, 4508-4509.

32. Hummelen, J. C.; Knight, B. W.; LePeq, F.; Wudl, F.; Yao, J.; Wilkins, C. L., Preparation and Characterization of Fulleroid and Methanofullerene Derivatives. J. Org. Chem. 1995, 60, 532-538.

33. Bendikov, M.; Wudl, F.; Perepichka, D. F., Tetrathiafulvalenes, Oligoacenenes, and Their Buckminsterfullerene Derivatives: The Brick and Mortar of Organic Electronics. Chem. Rev. 2004, 104, 4891-4946.

34. He, Y.; Li, Y., Fullerene Derivative Acceptors for High Performance Polymer Solar Cells. Phys. Chem. Chem. Phys. 2011, 13, 1970-1983.

35. Nardes, A. M.; Ferguson, A. J.; Whitaker, J. B.; Larson, B. W.; Larsen, R. E.; Maturová, K.; Graf, P. A.; Boltalina, O. V.; Strauss, S. H.; Kopidakis, N., Beyond PCBM: Understanding the Photovoltaic Performance of Blends of Indene-C60 Multiadducts with Poly(3Hexylthiophene). Adv. Funct. Mater. 2012, 22, 4115-4127.

36. Morinaka, Y.; Nobori, M.; Murata, M.; Wakamiya, A.; Sagawa, T.; Yoshikawa, S.; Murata, Y., Synthesis and Photovoltaic Properties of Acceptor Materials Based on the Dimerization of Fullerene C60 for Use in Efficient Polymer Solar Cells. Chem. Commun. 2013, 49, 3670-3672.

37. Ide, J.; Fazzi, D.; Casalegno, M.; Meille, S. V.; Raos, G., Electron Transport in Crystalline PCBM-Like Fullerene Derivatives: A Comparative Computational Study. J. Mat. Chem. C 2014, 2, 7313-7325.

38. Larson, B. W.; Whitaker, J. B.; Wang, X.-B.; Popov, A. A.; Rumbles, G.; Kopidakis, N.; Strauss, S. H.; Boltalina, O. V., Electron Affinity of Phenyl-C61-Butyric Acid Methyl Ester (PCBM). J. Phys. Chem. C 2013, 117, 14958-14964.

39. Frigerio, F.; Casalegno, M.; Carbonera, C.; Nicolini, T.; Meille, S. V.; Raos, G., Molecular Dynamics Simulations of the Solvent- and Thermal History-Dependent Structure of the PCBM Fullerene Derivative. J. Mater. Chem. 2012, 22, 5434-5443.

40. Machui, F.; Abbott, S.; Waller, D.; Koppe, M.; Brabec, C. J., Determination of Solubility Parameters for Organic Semiconductor Formulations. Macromol. Chem. Phys. 2011, 212, 21592165.

41. Mihailetchi, V. D.; van Duren, J. K. J.; Blom, P. W. M.; Hummelen, J. C.; Janssen, R. A. J.; Kroon, J. M.; Rispens, M. T.; Verhees, W. J. H.; Wienk, M. M., Electron Transport in a Methanofullerene. Adv. Funct. Mater. 2003, 13, 43-46.

42. Jeziorski, B.; Moszynski, R.; Szalewicz, K., Perturbation Theory Approach to Intermolecular Potential Energy Surfaces of Van Der Waals Complexes. Chem. Rev. 1994, 94, 1887-1930.

43. Hohenstein, E. G.; Sherrill, C. D., Efficient Evaluation of Triple Excitations in Symmetry-Adapted Perturbation Theory Via Second-Order M[O-Slash]Ller--Plesset Perturbation Theory Natural Orbitals. J. Chem. Phys. 2010, 133, 104107-104107.

44. Jurečka, P.; Černý, J.; Hobza, P.; Salahub, D. R., Density Functional Theory Augmented with an Empirical Dispersion Term. Interaction Energies and Geometries of 80 Noncovalent Complexes Compared with Ab Initio Quantum Mechanics Calculations. J. Comput. Chem. 2007, $28,555-569$. 
45. Marshall, M. S.; Burns, L. A.; Sherrill, C. D., Basis Set Convergence of the CoupledCluster Correction, $\mathrm{D}_{\mathrm{mp} 2}{ }^{\operatorname{ccsd}(\mathrm{T})}$ : Best Practices for Benchmarking Non-Covalent Interactions and the Attendant Revision of the S22, Nbc10, Hbc6, and Hsg Databases. J. Chem. Phys. 2011, 135, 194102-194110.

46. Turney, J. M.; Simmonett, A. C.; Parrish, R. M.; Hohenstein, E. G.; Evangelista, F. A.; Fermann, J. T.; Mintz, B. J.; Burns, L. A.; Wilke, J. J.; Abrams, M. L., et al., Psi4: An OpenSource Ab Initio Electronic Structure Program. WIREs: Comput. Mol. Sci. 2012, 2, 556-565. 47. Stewart, J. J. P., Optimization of Parameters for Semiempirical Methods V: Modification of Nddo Approximations and Application to 70 Elements. J. Mol. Model. 2007, 13, 1173-1213. 48. Frisch, M. J.; Trucks, G. W.; Schlegel, H. B.; Scuseria, G. E.; Robb, M. A.; Cheeseman, J. R.; Montgomery, J., J. A.;; Vreven, T.; Kudin, K. N.; Burant, J. C., et al. Gaussian 09 Revision D.01, A.02; Gaussian Inc.: Wallingford CT, 2009.

49. Girifalco, L. A.; Hodak, M., Van Der Waals Binding Energies in Graphitic Structures. Phys. Rev. B: Condens. Matter 2002, 65, 125404.

50. Berendsen, H. J. C.; Vanderspoel, D.; Vandrunen, R., GROMACS - a Message PassingParallel Molecular-Dynamics Implementation. Comput. Phys. Commun. 1995, 91, 43-56.

51. Hess, B.; Kutzner, C.; van der Spoel, D.; Lindahl, E., GROMACS 4: Algorithms for Highly Efficient, Load-Balanced, and Scalable Molecular Simulation. J. Chem. Theory Comput. 2008, 4, 435-447.

52. Jorgensen, W. L.; Maxwell, D. S.; Tirado-Rives, J., Development and Testing of the OPLS All-Atom Force Field on Conformational Energetics and Properties of Organic Liquids. $J$. Am. Chem. Soc. 1996, 118, 11225-11236.

53. Xu, Z.; Luo, H. H.; Tieleman, D. P., Modifying the OPLS-AA Force Field to Improve Hydration Free Energies for Several Amino Acid Side Chains Using New Atomic Charges and an Off-Plane Charge Model for Aromatic Residues. J. Comput. Chem. 2007, 28, 689-697.

54. Williams, M.; Tummala, N. R.; Aziz, S. G.; Risko, C.; Brédas, J.-L., Influence of Molecular Shape on Solid-State Packing in Disordered PC61BM and PC71BM Fullerenes. $J$. Phys. Chem. Lett. 2014, 5, 3427-3433.

55. Frenkel, D.; Smit, B., Understanding Molecular Simulation : From Algorithms to Applications / Daan Frenkel, Berend Smit. San Diego, Calif. ; London : Academic, [2nd ed.]: 2002.

56. Bissantz, C.; Kuhn, B.; Stahl, M., A Medicinal Chemist's Guide to Molecular Interactions. J. Med. Chem. 2010, 53, 5061-5084.

57. Tsao, M.-L.; Hadad, C. M.; Platz, M. S., Computational Study of the Halogen Atom-Benzene Complexes. J. Am. Chem. Soc. 2003, 125, 8390-8399.

58. Politzer, P.; Murray, J. S.; Clark, T., Halogen Bonding and Other S-Hole Interactions: A Perspective. Phys. Chem. Chem. Phys. 2013, 15, 11178-11189.

59. Sutton, C.; Marshall, M. S.; Sherrill, C. D.; Risko, C.; Bredas, J. L., Rubrene: The Interplay between Intramolecular and Intermolecular Interactions Determines the Planarization of Its Tetracene Core in the Solid State. J. Am. Chem. Soc. 2015, 137, 8775-8782.

60. Wishart, D.; Bigam, C.; Holm, A.; Hodges, R.; Sykes, B., 1h, 13c and 15n Random Coil $\mathrm{Nmr}$ Chemical Shifts of the Common Amino Acids. I. Investigations of Nearest-Neighbor Effects. J. Biomol. NMR 1995, 5, 67-81.

61. Jackson, N. E.; Chen, L. X.; Ratner, M. A., Solubility of Nonelectrolytes: A FirstPrinciples Computational Approach. J. Phys. Chem. B 2014, 118, 5194-5202. 
62. Schmidt, J. R.; Yu, K.; McDaniel, J. G., Transferable Next-Generation Force Fields from Simple Liquids to Complex Materials. Acc. Chem. Res. 2015, 48, 548-556.

63. McDaniel, J. G.; Schmidt, J. R., Physically-Motivated Force Fields from SymmetryAdapted Perturbation Theory. J. Phys. Chem. A 2013, 117, 2053-2066.

64. Parker, T. M.; Sherrill, C. D., Assessment of Empirical Models Versus High-Accuracy $\mathrm{Ab}$ Initio Methods for Nucleobase Stacking: Evaluating the Importance of Charge Penetration. $J$. Chem. Theory Comput. 2015, 11, 4197-4204.

65. Lee, C.-K.; Pao, C.-W., Nanomorphology Evolution of P3HT/PCBM Blends During Solution-Processing from Coarse-Grained Molecular Simulations. J. Phys. Chem. C 2014, 118, 11224-11233.

66. Makowski, M.; Czaplewski, C.; Liwo, A.; Scheraga, H. A., Potential of Mean Force of Association of Large Hydrophobic Particles: Towards the Nanoscale Limit. J. Phys. Chem. B 2010, 114, 993-1003.

67. Li, L.; Bedrov, D.; Smith, G. D., Repulsive Solvent-Induced Interaction between $\mathrm{C}_{60}$ Fullerenes in Water. Phys. Rev. E: Stat. Phys., Plasmas, Fluids, 2005, 71, 011502.

68. Tummala, N. R.; Morrow, B. H.; Resasco, D. E.; Striolo, A., Stabilization of Aqueous Carbon Nanotube Dispersions Using Surfactants: Insights from Molecular Dynamics Simulations. ACS Nano 2010, 4, 7193-7204.

69. Park, S. H.; Roy, A.; Beaupre, S.; Cho, S.; Coates, N.; Moon, J. S.; Moses, D.; Leclerc, M.; Lee, K.; Heeger, A. J., Bulk Heterojunction Solar Cells with Internal Quantum Efficiency Approaching 100\%. Nat. Photonics 2009, 3, 297-302.

70. Liang, Y.; Xu, Z.; Xia, J.; Tsai, S.-T.; Wu, Y.; Li, G.; Ray, C.; Yu, L., For the Bright Future-Bulk Heterojunction Polymer Solar Cells with Power Conversion Efficiency of 7.4\%. Adv. Mater. 2010, 22, E135-E138.

71. Bull, T. A.; Pingree, L. S. C.; Jenekhe, S. A.; Ginger, D. S.; Luscombe, C. K., The Role of Mesoscopic PCBM Crystallites in Solvent Vapor Annealed Copolymer Solar Cells. ACS Nano 2009, 3, 627-636.

72. Xie, Y.; Dutta, P.; Cengher, D.; Bommisetty, V.; Li, J.; Galipeau, D.; Qiao, Q. Q., Solvent Effect on the Morphology of P3HT/PCBM Films. in Organic Photovoltaics X, Edited by Zakya H. Kafafi; Lane, P. A., Proceedings of SPIE, Bellingham, WA, 2009, 2009; Vol. 7416, pp 74161Q-74161Q.

73. Liu, F.; Gu, Y.; Wang, C.; Zhao, W.; Chen, D.; Briseno, A. L.; Russell, T. P., Efficient Polymer Solar Cells Based on a Low Bandgap Semi-Crystalline DPP Polymer-PCBM Blends. Adv. Mater. 2012, 24, 3947-3951.

74. Lou, S. J.; Szarko, J. M.; Xu, T.; Yu, L.; Marks, T. J.; Chen, L. X., Effects of Additives on the Morphology of Solution Phase Aggregates Formed by Active Layer Components of HighEfficiency Organic Solar Cells. J. Am. Chem. Soc. 2011, 133, 20661-20663.

75. Liu, C.-M.; Su, M.-S.; Jiang, J.-M.; Su, Y.-W.; Su, C.-J.; Chen, C.-Y.; Tsao, C.-S.; Wei, K.-H., Distribution of Crystalline Polymer and Fullerene Clusters in Both Horizontal and Vertical Directions of High-Efficiency Bulk Heterojunction Solar Cells. ACS Appl. Mater. Inter. 2013, 5, 5413-5422.

76. MacKenzie, R. C. I.; Frost, J. M.; Nelson, J., A Numerical Study of Mobility in Thin Films of Fullerene Derivatives. J. Chem. Phys. 2010, 132, 064904-064906.

77. Savoie, B. M.; Rao, A.; Bakulin, A. A.; Gelinas, S.; Movaghar, B.; Friend, R. H.; Marks, T. J.; Ratner, M. A., Unequal Partnership: Asymmetric Roles of Polymeric Donor and Fullerene Acceptor in Generating Free Charge. J. Am. Chem. Soc. 2014, 136, 2876-2884. 
78. Anthopoulos, T. D.; Tanase, C.; Setayesh, S.; Meijer, E. J.; Hummelen, J. C.; Blom, P. W. M.; de Leeuw, D. M., Ambipolar Organic Field-Effect Transistors Based on a SolutionProcessed Methanofullerene. Adv. Mater. 2004, 16, 2174-2179.

79. Rispens, M. T.; Meetsma, A.; Rittberger, R.; Brabec, C. J.; Sariciftci, N. S.; Hummelen, J. C., Influence of the Solvent on the Crystal Structure of PCBM and the Efficiency of MDMOPPV:PCBM 'Plastic' Solar Cells. Chem. Commun. 2003, 2116-2118.

80. Casalegno, M.; Zanardi, S.; Frigerio, F.; Po, R.; Carbonera, C.; Marra, G.; Nicolini, T.; Raos, G.; Meille, S. V., Solvent-Free Phenyl-C61-Butyric Acid Methyl Ester (PCBM) from Clathrates: Insights for Organic Photovoltaics from Crystal Structures and Molecular Dynamics. Chem. Commun. 2013, 49, 4525-4527.

81. Dang, M. T.; Wantz, G.; Bejbouji, H.; Urien, M.; Dautel, O. J.; Vignau, L.; Hirsch, L., Polymeric Solar Cells Based on P3HT:PCBM: Role of the Casting Solvent. Sol. Energy Mater. Sol. Cells 2011, 95, 3408-3418.

82. $\mathrm{Hu}, \mathrm{S}$. The Impact of Selective Solvents on the Structure and Function Evolution in Solvent Annealed Organic Photovoltaics, Master's Thesis, The University of Tennessee, http://trace.tennessee.edu/utk gradthes/2425, 2013.

83. Chang, L.; Lademann, H. W. A.; Bonekamp, J.-B.; Meerholz, K.; Moulé, A. J., Effect of Trace Solvent on the Morphology of P3HT:PCBM Bulk Heterojunction Solar Cells. Adv. Funct. Mater. 2011, 21, 1779-1787.

84. Lee, C.-K.; Wodo, O.; Ganapathysubramanian, B.; Pao, C.-W., Electrode Materials, Thermal Annealing Sequences, and Lateral/Vertical Phase Separation of Polymer Solar Cells from Multiscale Molecular Simulations. ACS Appl. Mater. Inter. 2014, 6, 20612-20624.

85. Carrillo, J.-M. Y.; Kumar, R.; Goswami, M.; Sumpter, B. G.; Brown, W. M., New Insights into the Dynamics and Morphology of P3HT:PCBM Active Layers in Bulk Heterojunctions. Phys. Chem. Chem. Phys. 2013, 15, 17873-17882. 
$\underline{\text { Table of Contents Graphic }}$

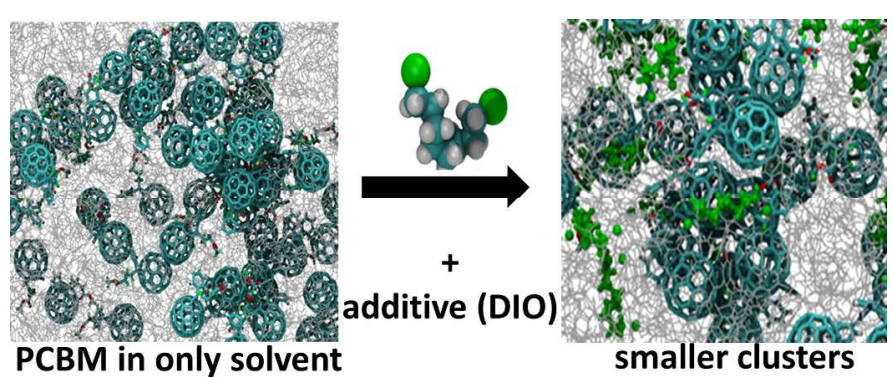

